\title{
Water Analysis via Portable X-ray Fluorescence Spectrometry
}

Delaina Pearson ${ }^{1}$, Somsubhra Chakraborty ${ }^{2}$, Bogdan Duda ${ }^{1}$, Bin Li $^{3}$, David C. Weindorf ${ }^{*}$, Shovik Deb $^{2}$, Eric Brevik ${ }^{4}$, D.P. Ray ${ }^{5}$

Key words: salinity, proximal sensors

\begin{abstract}
Rapid, in-situ elemental water analysis would be an invaluable tool in studying polluted and/or salt-impacted waters. Analysis of water salinity has commonly used electrical conductance (EC); however, the identity of the elements responsible for the salinity are not revealed using EC. Several studies have established the viability of using portable X-ray fluorescence (PXRF) spectrometry for elemental data analysis of soil, sediment, and other matrices. However, the accuracy of PXRF is known to be affected whilst scanning moisture-laden soil samples. This study used PXRF elemental data in water samples to predict water EC. A total of 256 water samples, from 10 different countries were collected and analyzed via PXRF, inductively coupled
\end{abstract}


21 plasma atomic emission spectroscopy (ICP-AES), and via a digital salinity bridge. The PXRF

22 detected some elements more effectively than others, but overall results indicated that PXRF can

23 successfully predict water $\mathrm{EC}$ via quantifying $\mathrm{Cl}$ in water samples (validation $\mathrm{R}^{2}$ and $\mathrm{RMSE}$ of

240.77 and $0.95 \log \mu \mathrm{S} \mathrm{cm}{ }^{-1}$, respectively). The findings of this study elucidated the potential of

25 PXRF for future analysis of pollutant and/or metal contaminated waters.

\section{INTRODUCTION}

Environmental quality assessment is of paramount importance as the world's population approaches eight billion people in the coming decades. Non-polluted soil and water for food production are among the most basic of human necessities. However, industrial development has resulted in widespread pollution and salinization of both soil and water resources (e.g., Pen-

32 Mouratov et al., 2008; Weindorf et al., 2013a; Rengasamy, 2006; Trujillo-González et al., 2016).

33 For example, Auchmoody and Walters (1988) documented the impact of brine spills on soils and 34 vegetation in the Allegheny National Forest of Northwestern Pennsylvania, noting that "brine 35 spills and accidental discharges pose serious environmental threats." Similarly, Vidakovic-Cifrek 36 et al. (2002) note that calcium bromide and calcium chloride are commonly prepared high

37 density brines used in oil exploration and production. However, they concede that accidental 38 releases of such salts can and do pollute adjacent groundwater and soil. Also, many pollutant 39 laden surface waters concern the suspension of metals bound to soil particles which are carried 40 into waterways as suspended solids. As recently as 2015, a major $\mathrm{Pb}$ contamination crisis 41 affected the public water supply of Flint, Michigan, USA. Globally, saline and sodic soils 42 constitute 397.1 and 434.3 million ha (UN-FAO, 2016) while polluted soils are found at 43 hundreds of thousands of sites worldwide. For example in Europe, heavy metals from smelting 
44 activities account for $34.8 \%$ of polluted soils (IASS, 2012). This pollution, in turn, represents a 45 significant threat to human health (Brevik and Sauer, 2015).

Soil and water salinity are intrinsically linked as the former relies on slurries or saturated

47 pastes whereby salts precipitated in soil dissolve into solution and are measured in the aqueous

48 phase. Traditional analysis of water salinity has commonly used electrical conductance. For 49 decades, the Solubridge (a rudimentary, analog salinity bridge) was the preferred technology 50 (Salinity Laboratory Staff, 1954), whereas more recently, the use of digital conductivity meters 51 has become commonplace. Conductivity meters rely on the fact that dissolved cations and anions 52 in aqueous solution effectively bolster the transmission of electric current (Rhoades, 1996). 53 Thus, the more dissolved salt present in aqueous samples, the greater the electrical conductivity 54 (EC). However, salinity meters only provide information on the total dissolved solutes found in 55 water; they do not identify the types of cations/anions which contribute to the salinity of the 56 sample. Elemental identification/quantification has been reliant first upon flame photometry, 57 then atomic absorption spectroscopy (AAS) (Wright and Stuczynski, 1996), and finally 58 inductively coupled plasma atomic emission spectroscopy (ICP-AES) (Soltanpour et al., 1996). 59 Colorimetry and other wet chemistry techniques may also be used for the identification and 60 qualitative estimation of certain elements (e.g., Kuo, 1996). However, recent advances in 61 portable X-ray fluorescence (PXRF) spectrometry have provided a field portable instrument 62 capable of making elemental determinations in-situ in minutes.

Applied to soil and environmental science, several methods have been established for PXRF 64 use in soil, sediment, and other matrices; among them Method 6200 (US-EPA, 2007), a recently 65 established method by the Soil Survey Staff (2014), and a method by the Soil Science Society of 66 America (Weindorf and Chakraborty, 2016). Specific applications of PXRF for soil and 
67 environmental quality analysis include quantification of cation exchange capacity (Sharma et al.,

68 2015), soil reaction ( $\mathrm{pH})$ (Sharma et al., 2014), enhanced soil horizonation (Weindorf et al.,

69 2012), plant essential nutrients (McLaren et al., 2012), and the spatial variability of pollutants

70 (Paulette et al., 2015; Clark and Knudsen, 2014). However, three studies in particular indicate

71 the possible utility of PXRF for elemental determination in water samples. Weindorf et al.

72 (2013b) used PXRF for the determination of gypsum $\left(\mathrm{CaSO}_{4} \cdot 2 \mathrm{H}_{2} \mathrm{O}\right)$ with $\mathrm{Ca}$ and $\mathrm{S}$ as proxy

73 elements for gypsum content. Using simple linear regression, PXRF-determined $\mathrm{S}$ and $\mathrm{Ca}$

74 predicted total gypsum content, as determined by thermogravimetry, with $\mathrm{R}^{2}$ of 0.91 and 0.88 ,

75 respectively. Similarly, Swanhart et al. (2014) used Cl as a proxy for saturated paste soil salinity

76 and found a calibration $\mathrm{R}^{2}$ of 0.83 , with and even stronger $\mathrm{R}^{2}$ of 0.90 using multiple elements

77 and multiple linear regression. As both of these represent salts present in soil, there is reason to

78 believe that PXRF may be effective in determining water salinity using single or multiple

79 elements as proxies (e.g., Cl, Ca, S, K). Finally, Eksperiandova et al. (2002) used PXRF for the

80 analysis of waste water by combining the water with gelatin and agar. Evaluating low levels of

81 metals $\left(<400 \mathrm{mg} \mathrm{L}^{-1}\right)$ in solution, they obtained reasonably good determination via PXRF

82 (relative standard deviation up to $0.08 \%$ ). As such, we conducted preliminary PXRF scans of

83 several brine well water samples from North Dakota and found reasonable predictability of EC;

84 data which established the precedent for the larger study presented herein.

In fairness, the PXRF does present certain limitations (Weindorf et al., 2014) which need to

be considered for aqueous sample assessment. Moisture is known to denude the fluorescent

87 energy of various elements, potentially interfering with accuracy (Weindorf et al., 2014). Also

suspended sediments, themselves rife with abundant elements, would likely bias PXRF results. 
transmissivity and filtration/centrifugation of samples to remove any suspended sediments would

91 seem logical means toward overcoming such limitations.

92 Given the number of polluted and/or salt impacted waters found worldwide, the evaluation of

93 PXRF as a rapid analytical technique for aqueous samples appears timely. If proven accurate for

94 the assessment and quantification of dissolved solutes, it could be an important step toward 95 consideration of more advanced aqueous chemistries inclusive of pollutants (e.g., heavy metals)

96 and suspended solids. As such, the objective of this research was to evaluate the potential of

97 PXRF in predicting water EC. We hypothesize that PXRF will successfully detect elements

98 which can be used to predict water salinity and show strong correlation to electrical conductivity

99 data across a wide range of salinity concentrations.

\section{MATERIALS AND METHODS}

\section{Sample collection}

A total of 256 water samples were collected from 10 different countries (Belgium, Bolivia,

104 Samples from within the United States were collected from Alaska, Arizona, California,

105 Colorado, Florida, Minnesota, Nevada, New Mexico, Oklahoma, Texas, Tennessee, Utah, and 106 Wyoming. Table 1 shows the distribution of sample collection. Waters collected were as follows: 107 lake (71), swimming pool (7), river (64), sea (3), tap (84), and well (27). Each sample was placed 108 in a new $120 \mathrm{ml}$ plastic bottle, sealed, and refrigerated at $4^{\circ} \mathrm{C}$ prior to analysis. Samples were 109 transported to the Pedology laboratory at Texas Tech University (Lubbock, TX, USA) for 110 analysis.

\section{Laboratory analysis}


Prior to analysis, samples were allowed to return to room temperature $\left(20^{\circ} \mathrm{C}\right)$. Most samples 113 contained no visually observable suspended solids (Fig. 1a); for those few samples that did, 114 filtration and centrifugation was undertaken prior to analysis. Electrical conductance was 115 measured with a Traceable ${ }^{\mathrm{TM}}$ expanded range digital conductivity meter (Fisher Scientific, 116 Hampton, NH, USA). The conductance probe was thoroughly washed with deionized water 117 between samples. Performance of the salinity bridge was assured via assessment of standard 118 conductance solutions.

119 Prior to PXRF analysis, each sample was placed in a Series 1400 plastic sample cup 120 (Chemplex Industries, Palm City, FL, USA), then covered with Prolene ${ }^{\circledR}$ thin-film (Chemplex 121 Industries, Palm City, FL, USA) (Fig. 1a). A Delta Premium (DP-6000) PXRF (Olympus-Innov122 X; Waltham, MA, USA), was used to conduct the analyses. Prior to scanning the PXRF was 123 calibrated with a standard 316 metal alloy target placed in front of the aperture. Once a 124 calibration check with the alloy was successful, the instrument was positioned into a proprietary 125 test stand (Fig. 1b) for scanning; the test stand shields the operator from any errant X-radiation. 126 Samples were positioned on the sample stage such that the water was placed directly over the 127 PXRF aperture. The PXRF was operated in Soil Mode, a configuration capable of scanning $~ 25$ 128 different elements. In Soil Mode, we configured each of the three beams to scan for 30 sec such 129 that one complete scan of a given sample was completed in $90 \mathrm{sec}$. Beams one and two were 130 both operated at $40 \mathrm{KeV}$, whilst beam three was operated at $15 \mathrm{KeV}$. Two types of data were 131 downloaded from the instrument following scanning: 1) elemental data (as reported by the 132 software as configured), and 2) raw spectral data reporting counts and fluorescent energy (KeV) 133 for each scan. The former is a simpler approach for "off the shelf" application, while the latter 134 provides data for advanced spectral analysis. While the PXRF can detect multiple elements 
135 simultaneously, concentrations below the detection limit are problematic as they cause 136 discontinuity in the number of samples across the dataset. In this study, many elements were

137 uniquely identified in different water samples, but only $\mathrm{Ca}, \mathrm{Cl}$, and $\mathrm{K}$ were reported continuously 138 across all samples.

139 Samples were also subjected to inductively coupled plasmas atomic emission spectroscopy 140 (ICP-AES) analysis via a Genesis model instrument (Spectro Analytical Instruments, Irvine, CA, 141 USA) (Soltanpour et al., 1996). Elemental data reported via ICP-AES included: Al, As, B, Cd, $142 \mathrm{Ca}, \mathrm{Cl}, \mathrm{Cu}, \mathrm{Fe}, \mathrm{K}, \mathrm{Pb}, \mathrm{Mg}, \mathrm{Mn}, \mathrm{Mo}, \mathrm{Na}, \mathrm{Ni}, \mathrm{P}, \mathrm{S}, \mathrm{Se}$, and Zn.

143 Separately, two different calibration curves were constructed using reagent grade $\mathrm{KCl}$ and $144 \mathrm{NaCl}$ mixed with deionized water. Concentrations were set as follows: $0.001 \%, 0.01 \%, 0.05 \%$, $1450.10 \%, 0.50 \%, 1 \%, 2 \%$, and $5 \%$. These standard solutions were evaluated for electrical 146 conductance, and for elemental concentration via both PXRF and ICP.

\section{Statistical analysis} 2.11.0 (R Development Core Team, 2014). The normality of EC residuals was checked by the Shapiro-Wilk test. Notably, EC values were positively skewed (Pearson skewness coefficient 4.53), while Box-Cox conversion (Box and Cox, 1964) using log transformed EC values were

152 able to conform the data to a normal distribution. Further, the three PXRF measured elements $153(\mathrm{Cl}, \mathrm{K}$, and $\mathrm{Ca})$ were log transformed. Principal component analysis (PCA) was executed via $\mathrm{R}$ 154 version 2.11.0 using the 'prcomp' function to visualize the clustering of water samples from 155 different sources. Optimal number of principal components (PC) was decided from a screeplot. 
Piecewise linear regression (PLR) was employed to model water EC using three PXRF measured elements $(\mathrm{Cl}, \mathrm{K}$ and $\mathrm{Ca})$. A few observations with missing values were deleted a priori and the rest $(\mathrm{n}=252)$ were randomly split into training set $(176$ samples, $\sim 70 \%)$ and test set $(76$ 159 observations, $\sim 30 \%$ ). PLR, also known as segmented regression, partitions the explanatory variable into intervals and fits line segment to each interval. The boundaries between the 161 intervals are called the breakpoints. Like nonlinear regression, PLR is particularly useful to 162 model an abrupt change of relationship between a response and a predictor. However, since the 163 linear model is fitted for each interval, the fitted PLR model can be easily presented by equations 164 and is therefore highly interpretable. In this study, we used the PLR with only one breakpoint for 165 PXRF-measured $\mathrm{Cl}, \mathrm{K}$, and $\mathrm{Ca}$. The location of the breakpoint, intercept, and slopes were chosen 166 to minimize the sum of squared errors (SSE). In this study, the PLR was executed by using the 167 segmented package (version: 0.5-1.4) in R, produced by Muggeo (2008). Model predictability 168 was compared via $R^{2}$, RMSE, Akaike information criterion (AIC) and Bayesian information 169 criterion (BIC) values (Akaike, 1973). In general, the best models show the smallest AIC and 170 BIC values.

\section{$171 \quad$ PXRF spectral analysis}

172 Furthermore, PXRF spectra were baseline corrected and smoothed using a Savitzky-Golay 173 first order polynomial via Unscrambler ${ }^{\circledR} \mathrm{X} 10.3$ (CAMO Software Inc., Woodbridge, NJ). PXRF $174 \mathrm{~K} \alpha$ emission lines of $\mathrm{Cl}(2.62 \mathrm{KeV}), \mathrm{K}(3.31 \mathrm{KeV})$, and $\mathrm{Ca}(3.69 \mathrm{KeV})$ were separated using 175 only Beam $3(15 \mathrm{KeV})$ under Soil Mode. We followed the method proposed by Sacristán et al. 176 (2015) and calculated the full width at half maximum (FWHM) and the maximum height $\left(\mathrm{H}_{\max }\right)$

177 of $\mathrm{Cl}, \mathrm{K}$, and $\mathrm{Ca}$ peaks using Origin pro (OriginLab, MA, USA) for their subsequent use to 178 predict water EC. 


\section{RESULTS AND DISCUSSION}

\section{Water chemistry}

Summary statistics of different parameters of assayed water samples are presented in Table 2. As expected, results exhibited substantial variation in the EC of analyzed water samples, from very low $\left(1.33 \mu \mathrm{S} \mathrm{cm}^{-1}\right)$ to extremely high $\left(157,600.00 \mu \mathrm{S} \mathrm{cm}^{-1}\right)$, with a mean value of $7,837.55$ $\mu \mathrm{S} \mathrm{cm}^{-1}$ (Table 2). Notably, this study was based on a factory calibrated PXRF instrument in 'Soil Mode' which showed several folds higher elemental concentration for $\mathrm{Cl}, \mathrm{K}$, and $\mathrm{Ca}$ than ICP-based results despite exhibiting reasonable agreement between PXRF and ICP results (Table 3; Fig. 2). This variation was perhaps due to the soil mode calibration which is not targeted to a water matrix. Moreover, higher elemental enrichment in water may have led to excessive selfabsorption. Thus, it can be concluded that there is need for reliable standards focusing on water matrix to reduce this variation.

\section{Principal Component Analysis}

Principal component analysis was applied to the PXRF reported $\mathrm{Cl}, \mathrm{K}$, and $\mathrm{Ca}$ concentrations (Fig. 3). The first two leading PCs constituted over 95\% of the elemental variation (Fig. 3a), implying that using a PC1 vs PC2 plot was adequate to describe the variations among three PXRF variables (Fig. 3b). While PC1 was dominated by the PXRF-Cl (loading coefficient: 0.91), PC2 was dominated by the difference between PXRF-Ca and PXRF-K. The PC1 vs PC2 plot produced certain clustering of data, so that differentiation between water sources was readily apparent. For instance, while samples from sea showed close clustering, lake and well water samples were highly spread out along PC1, indicating that lake and well samples had large

variations among PRXF-Cl (51-56,739 $\mathrm{mg} \mathrm{kg}^{-1}$ and 48-300 $\mathrm{mg} \mathrm{kg}^{-1}$ for lake and well samples, 
201 respectively). While comparing lake and well water samples, lake samples had relatively large

202 PC2 scores, indicating a larger difference between PRXF-Ca and PRXF-K. Moreover, pool

203 samples had relatively low PRXR-Cl contents, since they exhibited smaller values along PC1.

204 Notably, tap water samples appeared well-mixed with lake samples. KCl-standard samples were

205 clustered together, while NaCl-standards were relatively spread out. In general, well water

206 samples appeared to be away from most of the other samples from different sources. Importantly,

207 the PC score plot indicated the compositional differences between water samples from different

208 sources.

209

\section{Regression model results}

210 By observing the scatter plots with added fitted line(s) from the models (Fig. 4), the use of 2-

211 segmented PLR for calibrating soil EC with PXRF elements seemed prudent since most of the

212 time soil or water-elemental associations represent intricate groupings of linear segments of

213 variable slope. Overall, the EC was estimated with good accuracy with PXRF-Cl (calibration $R^{2}$

$214=0.77$, calibration $\left.\mathrm{RMSE}=0.89 \log \mu \mathrm{S} \mathrm{cm}^{-1}\right)($ Table 3$)$, which has been noted before elsewhere

215 (Swanhart et al., 2014). Validation results very much followed the calibration outcomes with

216 identical coefficient of determination (0.77) and close validation RMSE $\left(0.95 \log \mu \mathrm{S} \mathrm{cm}^{-1}\right)$,

217 implying high enrichment of chloride salts in water samples. Whilst the water EC prediction

218 results were not as high as that obtained for soil EC using PXRF-Cl (Swanhart et al., 2014), the

219 results were encouraging, considering the matrix interference, denudation of the fluorescent

220 energy of various element by water, and that $\sim 10 \%$ of the water $\mathrm{Cl}$ contents were either close or

221 less than the detection limit of PXRF (60-100 ppm), enhancing the standard error of

222 measurements. Contrariwise, no reasonable agreements were found between EC and PXRF-K

223 (calibration $R^{2}=0.41$, calibration $\mathrm{RMSE}=1.41 \log \mu \mathrm{S} \mathrm{cm}^{-1}$ ) and $\mathrm{Ca}$ (calibration $R^{2}=0.41$, 
224 calibration $\mathrm{RMSE}=1.40 \log \mu \mathrm{S} \mathrm{cm}^{-1}$ ), possibly due to matrix effects. Furthermore, PXRF-Cl 225 model was considered preferable with deference to model accuracy (Table 4), due to its 226 comparatively lower AIC (468.74) and BIC (484.59) values. Owing to PXRF's inability to

227 directly quantify $\mathrm{Na}^{+}$because of its small, stable electron cloud, acceptable agreement between 228 PXRF-Cl and water EC justified the possible incidences of halite $(\mathrm{NaCl})$ in water samples 229 (Aldabaa et al., 2015).

230 Plots of measured vs. PXRF predicted EC values are presented in Fig. 5. In general, all 231 models showed overestimation at lower EC values and underestimation at higher values. Several 232 of these overestimations occurred because of the relative scarcity of observations with low EC 233 values. The equations for all three PLR models are presented in Table 5.

\section{$234 \quad$ Limitations with PXRF spectra analysis}

Fig. 6 represents stacked and some log-transformed isolated examples of baseline corrected and smoothed XRF emission lines of $\mathrm{Cl}(2.62 \mathrm{KeV}), \mathrm{K}(3.31 \mathrm{KeV})$, and $\mathrm{Ca}(3.69 \mathrm{KeV})$. Notably, 237 while comparing all three stacked XRF spectra indicating different elemental concentrations of $238 \mathrm{Cl}, \mathrm{K}$, and $\mathrm{Ca}$, most of them could not be distinguished from each other despite wider ranges of 239 elemental concentrations in water samples (Table 2). Without log-transformation, most of the 240 data were actually in the bottom of the plot. For example, in PRXF-K (Fig. 6b), 95\% of the 241 samples had the peak value < 253. Note that, on log-transformed PXRF-Cl, Ca, and K spectra, 242 only PXRF-Ca bumps produced FWHM values while most of PXRF-Cl bumps were unable to 243 generate FWHM values due to their multi-modal shape. Besides, most of the PXRF-K bumps 244 were monotonic and thus unsuitable to deduce the FWHM values. Moreover, using $\mathrm{H}_{\max }$ 245 representing changes in elemental concentrations, no better correlation was obtained than using 246 elemental results (data not shown). Thus, the postulation of Sacristán et al. (2015) that using 
$247 \mathrm{H}_{\max }$ or FWHM could be a fast and easy quantification method without complex data processing 248 and matrix effects, may not be generalized and warrants more studies to find the suitable spectral 249 preprocessing methods.

The results from this study implies that there is substantial potential of employing PXRF for rapid water salinity quantification or at least for screening purposes which require moderate 252 precision. The predictability can be enhanced with increasing variability in $\mathrm{Cl}$ concentrations in 253 the water samples. Given these results, PXRF shows potential as an effective approach for rapid, 254 on-site assessment of heavy metals and/or other pollutants in waters. Clearly, this is the next line 255 of approach warranting investigation. It is widely known that "heavier" elements are more easily 256 quantified by PXRF owing to a larger electron cloud. In soils, limits of detection for such 257 elements can be as low as $\sim 5 \mathrm{mg} \mathrm{kg}^{-1}$. Another modification which warrants further investigation 258 is longer scanning time. However, the increased accuracy by such extended scanning times must 259 be considered against the alacrity gained by using PXRF. Finally, as this line of inquiry 260 proceeds, fine tuning of PXRF fluorescence energy spectra can be undertaken in support of 261 developing a "Water Mode" on the PXRF instrument for future testing. Such a configuration 262 would intrinsically consider the low density matrix of the water being scanned such that other 263 elemental signatures could potentially be parsed from the fluorescent energy.

The authors concede that water salinity assessment via electrical conductivity may be just as easy as the use of PXRF. However, PXRF does provide actual elemental concentration $(\mathrm{Cl})$ 266 which may be useful in identifying certain types of salt(s) dissolved in solution; information not 267 provided by simple electrical conductivity assessment. That notwithstanding, the key novelty of 268 this study is the fact that water samples can be scanned via PXRF with significant statistical 269 relationships to standard laboratory techniques. To our knowledge, this represents the first such 
270 study of PXRF assessment of water samples. Clearly, more work needs to be done. But the

271 potential of PXRF for future analysis of pollutant and/or metal contaminated waters has been

272 established by protocols presented in the context of the present study.

\section{CONCLUSIONS}

275 This present study was a proof of concept demonstration and presented an easy and

276 convenient PXRF protocol for quantifying water $\mathrm{EC}$ with $\mathrm{Cl}, \mathrm{K}$, and $\mathrm{Ca}$. Results show that 277 combining 2-segmented PLR models with PXRF-Cl produced acceptable prediction accuracy for 278 water EC while no realistic agreements were observed between water EC and PXRF-K and Ca. 279 This was possibly due to matrix effects represented by absorption and secondary fluorescence. 280 The poor EC predictability while using PXRF spectral parameters like FWHM and $\mathrm{H}_{\max }$ 281 underlies the need for better spectral PXRF preprocessing methods and factory calibration of 282 PXRF, possibly to include the development of a "water mode." However, the results obtained are 283 encouraging and point to the potential of PXRF for future rapid analysis of water samples in-situ. 284 Study of its potential for quickly screening water samples for heavy metals and/or other 285 pollutants is warranted.

\section{ACKNOWLEGEMENTS}

The authors are grateful for seed funding of this project from the US Forest Service (Forest

289 Service Agreement No. 15-CS-11011800-013) and support from the BL Allen Endowment in 290 Pedology at Texas Tech University. The authors also gratefully acknowledge Carla Millares, 
291 Todd Carr, Laura Paulette, Guiseppe Corti, Stefania Cocco and Carmen Waldo for assistance in 292 sample collection.

\section{REFERENCES}

295

296

297

298

299

300

301

302

303

304

305

306

307

308

309
Akaike, H., 1973. Information theory and the extension of the maximum likelihood principle. In: Petrov, V.N., Csaki, F. (Eds.), 2nd International Symposium on Information Theory. Academiai Kiadó, Budapest. pp. 267--281

Aldabaa, A.A.A., Weindorf, D.C., Chakraborty, S., Sharma, A., Li, B., 2015. Combination of proximal and remote sensing methods for rapid soil salinity quantification. Geoderma 239-240, 34-46.

Auchmoody, L.R., Walters, R.S., 1988. Revegetation of a brine-killed forest site. Soil Science Society of America Journal 52, 277-280.

Box, G.E.P., Cox, D.R., 1964. An analysis of transformations. J. R. Stat. Soc. Series B Stat. Methodol. 26, 211-252.

Brevik, E.C., Sauer, T.J., 2015. The past, present, and future of soils and human health studies. SOIL 1, 35-46. doi:10.5194/soil-1-35-2015.

Clark, J.J., Knudsen, A.C., 2014. Extent, characterization, and sources of soil lead contamination in small-urban residential neighborhoods. Journal of Environmental Quality 42, 14981506. 
Eksperiandova, L.P., Blank, A.B., Makarovskaya, Y.N., 2002. Analysis of waste water by x-ray fluorescence spectrometry. X-Ray Spectrometry 31(3), 259-263.

Institute for Advanced Sustainability Studies. 2013. Soil contamination: A severe risk for the environment and human health. IASS special publication. $5 \mathrm{p}$.

Kuo, S., 1996. Phosphorus. In: Sparks et al. (Eds.), Methods of soil analysis - Part 3, Chemical methods. Soil Science Society of America, Madison, WI. p. 869-919.

McLaren, T.I., Guppy, C.N., Tighe, M.K., 2012. A rapid and nondestructive plant nutrient analysis using portable X-ray fluorescence. Soil Science Society of America Journal 76, 1446-1453.

Muggeo, V.M.R., 2008. Segmented: an R package to fit regression models with broken-line relationships. R News 8(1), 20-25.

Paulette, L., Man, T., Weindorf, D.C., Person, T., 2015. Rapid assessment of soil and contaminant variability via portable x-ray fluorescence spectroscopy: Copşa Mică, Romania. Geoderma 243-244, 130-140.

Pen-Mouratov, S., Shukurov, N., Steinberger, Y., 2008. Influence of industrial heavy metal pollution on soil free-living nematode population. Environmental Pollution 152, 172-183.

R Development Core Team. 2014. R: a language and environment for statistical computing. R Found. Stat. Comput. Vienna, Austria (Available online with updates at http//www.cran.r-project.org, Verified on January 6, 2016).

Rengasamy, P., 2006. World salinization with emphasis on Australia. Journal of Experimental Botany 57, 1017-1023. 
331

332

333

334

335

336

337

338

339

340

341

342

343

344

Rhoades, J.D., 1996. Salinity: Electrical conductivity and total dissolved solids. In: Sparks et al. (Eds.), Methods of soil analysis - Part 3, Chemical methods. Soil Science Society of America, Madison, WI. p. 417-435.

Sacristán, D., Viscarra Rossel, R.A., Recatalá, L., 2016. Proximal sensing of Cu in soil and lettuce using portable X-ray fluorescence spectrometry. Geoderma 265, 6-11.

Salinity Laboratory Staff. 1954. Diagnosis and improvement of saline and alkali soils. Agricultural Handbook No. 60. US Department of Agriculture, Washington, DC.

Sharma, A., Weindorf, D.C., Man, T., Aldabaa, A., Chakraborty, S., 2014. Characterizing soils via portable x-ray fluorescence spectrometer: 3. Soil reaction $(\mathrm{pH})$. Geoderma 232-234, $141-147$.

Sharma, A., Weindorf, D.C., Wang, D.D., Chakraborty, S., 2015. Characterizing soils via portable x-ray fluorescence spectrometer: 4. Cation exchange capacity (CEC). Geoderma 239-240, 130-134.

Soil Survey Staff. 2014. Soil survey field and laboratory methods manual. Soil Survey Investigations Report No. 51, Version 2. USDA-NRCS, Lincoln, NE.

Soltanpour, P.N., Johnson, G.W., Workman, S.M., Jones, J.B., Miller, R.O., 1996. Inductively coupled plasma emission spectrometry and inductively couple plasma-mass spectrometry. In: Sparks et al. (Eds.), Methods of soil analysis - Part 3, Chemical methods. Soil Science Society of America, Madison, WI. p. 91-139. 
Swanhart, S., Weindorf, D.C., Chakraborty, S., Bakr, N., Zhu, Y., Nelson, C., Shook, K., Acree, A., 2014. Soil salinity measurement via portable x-ray fluorescence spectrometry. Soil Science 179(9), 417-423.

Trujillo-González, J.M., Torres-Mora, M.A., Keesstra, S., Brevik, E.C., Ballesta, R.J., 2016. Heavy metal accumulation related to population density in road dust samples taken from urban sites under different land uses. Science of the Total Environment 553, 636-642.

United Nations - Food and Agricultural Organization. 2016. Extent of salt-affected soils. Available at http://www.fao.org/soils-portal/manejo-del-suelo/manejo-de-suelosproblematicos/suelos-afectados-por-salinidad/more-information-on-salt-affected-soils/es/ (verified 10 Mar. 2016).

Vidakovic-Cifrek, Z., Pavlica, M., Regula, I., Papes, D., 2002. Cytogenetic damage in shallot (Allium cepa) root meristems induced by oil industry "high-density brines". Archives of Environmental Contamination and Toxicology 43, 284-291.

Weindorf, D.C., Chakraborty, S., 2016. Portable X-ray fluorescence spectrometry analysis of soils. Hirmas, D. (Ed.), Methods of soil analysis. Soil Science Society of America, Madison, WI. p. 1-8. doi:10.2136/vzj2015.09.0132.

Weindorf, D.C., Paulette, L., Man, T., 2013a. In-situ assessment of metal contamination via portable x-ray fluorescence spectroscopy: Zlatna, Romania. Environmental Pollution 182, 92-100. 
369 Weindorf, D.C., Herrero, J., Castañeda, C., Bakr, N., Swanhart, S., 2013b. Direct soil gypsum 370 quantification via portable x-ray fluorescence spectrometry. Soil Science Society of America Journal 77, 2071-2077.

372 Weindorf, D.C., Bakr, N., Zhu, Y., 2014. Advances in portable X-ray fluorescence (PXRF) for 373 environmental, pedological, and agronomic applications. Advances in Agronomy 128, 1374 45.

375 Weindorf, D.C., Zhu, Y., Haggard, B., Lofton, J., Chakraborty, S., Bakr, N., Zhang, W., 376 Weindorf, W.C., Legoria, M., 2012. Enhanced pedon horizonation using portable x-ray fluorescence spectroscopy. Soil Science Society of America Journal 76(2), 522-531.

378 Wright, R.J., Stuczynski, T., 1996. Atomic absorption and flame emission spectrometry. In: Sparks et al. (Eds.), Methods of soil analysis - Part 3, Chemical methods. Soil Science Society of America, Madison, WI. p. 65-90. 
382 Fig. 1. a) Water samples placed in plastic cups and sealed with Prolene thin-film; b) hooded test 383 stand for scanning water samples while shielding the operator from stray X-radiation.

384 Fig 2. Box and whisker plots showing elemental concentrations of $\mathrm{Cl}$, $\mathrm{K}$, and $\mathrm{Ca}$ in water 385 samples as derived from both inductively coupled plasma (ICP) atomic emission spectroscopy 386 and portable X-ray fluorescence (PXRF) spectrometry. Plots show the first quartile, second 387 quartile, median, third quartile, fourth quartile, and mean values.

388 Fig 3. a) Screeplot showing proportion of variance explained by principal components, and b) 389 PC1 vs. PC2 score plot exhibiting source-wise water sample clustering.

390 Fig. 4. Scatterplots of water EC values with added fitted line(s) from piecewise linear regression 391 using PXRF elemental data.

392 Fig. 5. Plots of observed vs. model predicted EC values showing both calibration and validation 393 data (with dotted 1:1 line).

394 Fig. 6. Stacked non-transformed and select log-transformed examples of baseline corrected and 395 smoothed XRF emission lines of a) $\mathrm{Cl}(2.62 \mathrm{KeV})$, b) $\mathrm{K}(3.31 \mathrm{KeV})$ and c) $\mathrm{Ca}(3.69 \mathrm{KeV})$. 

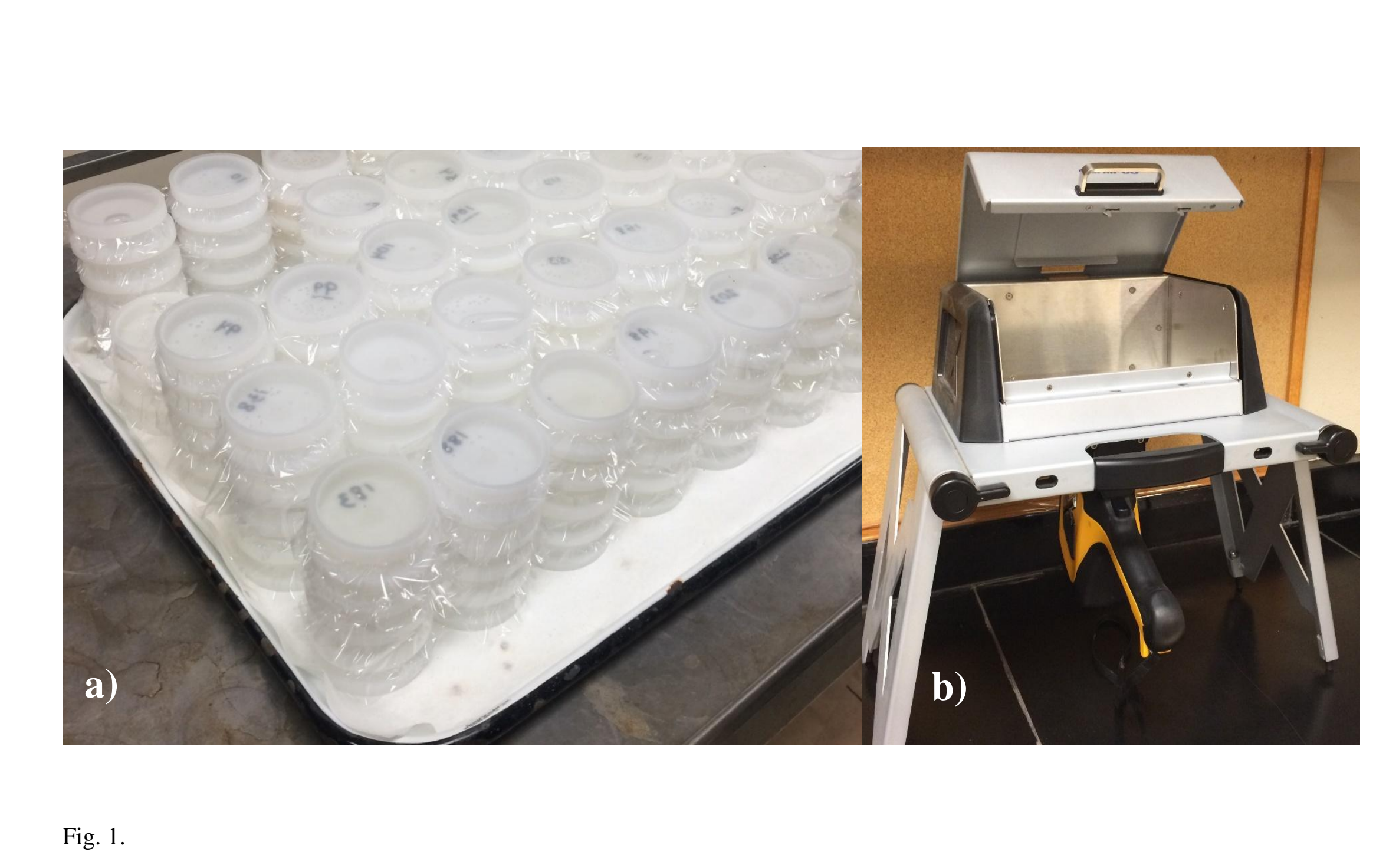

-

\author{
.
}

.

.
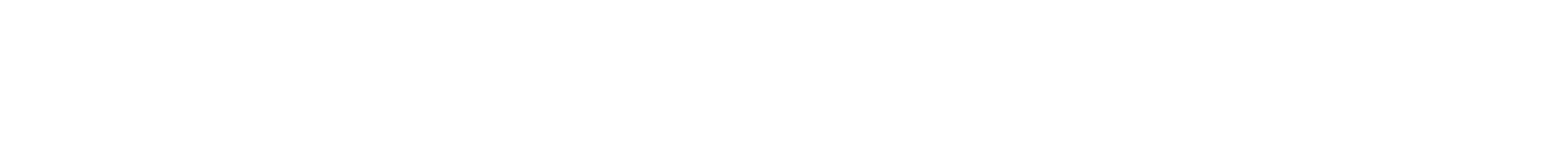

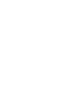

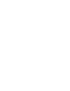
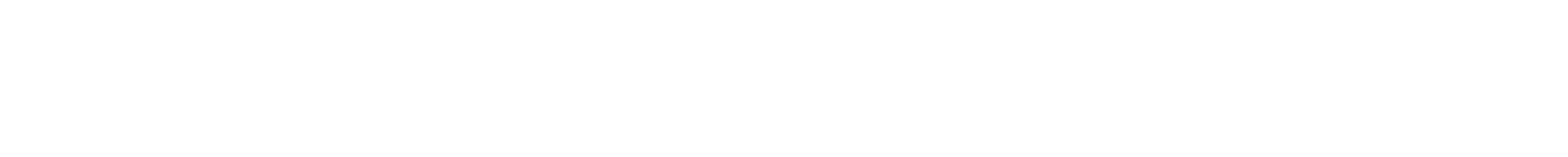

\footnotetext{
Fig. 1.

Fig. 1.

Fig. 1.
}
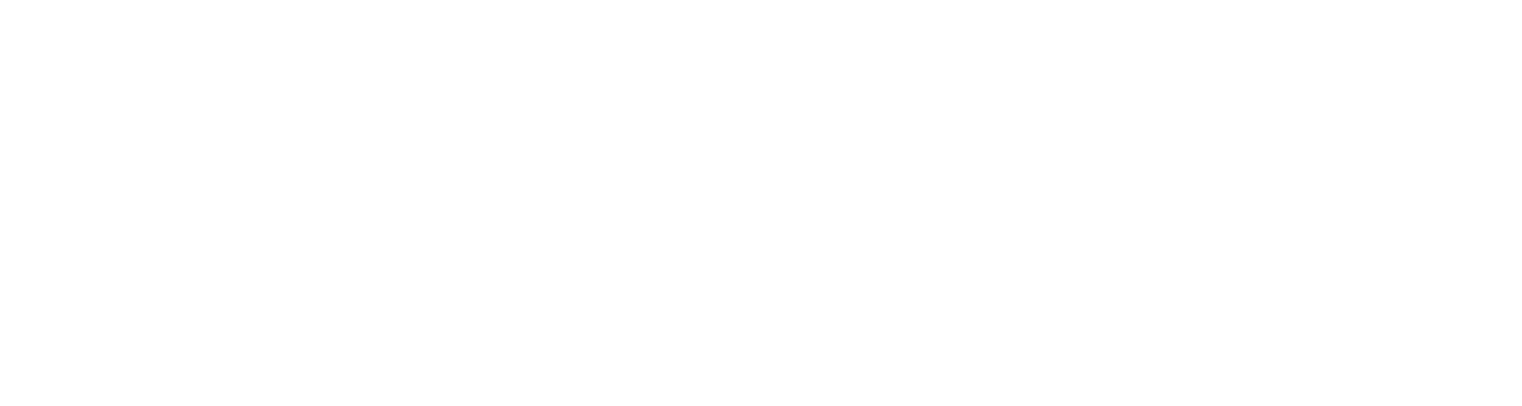


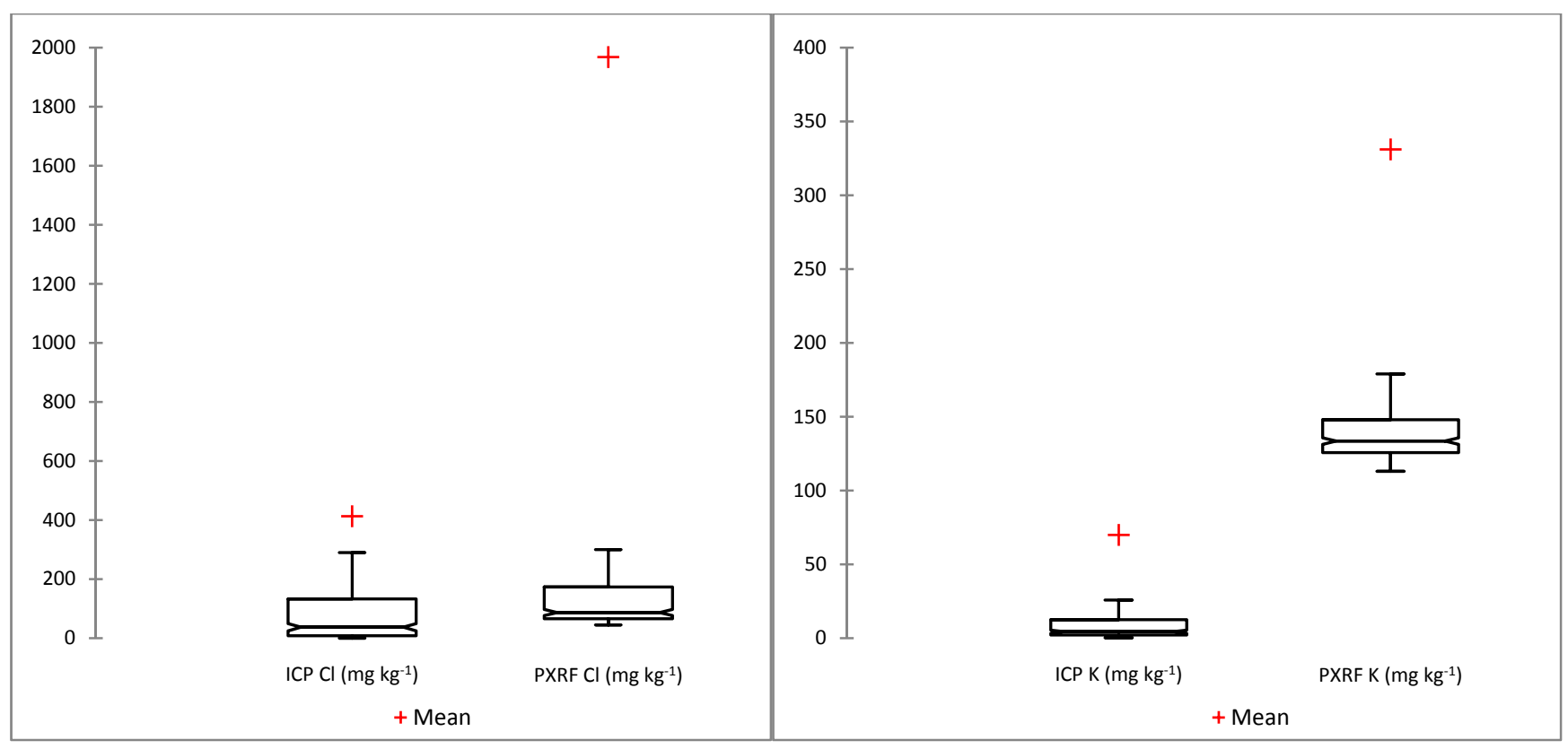

Fig. 2.

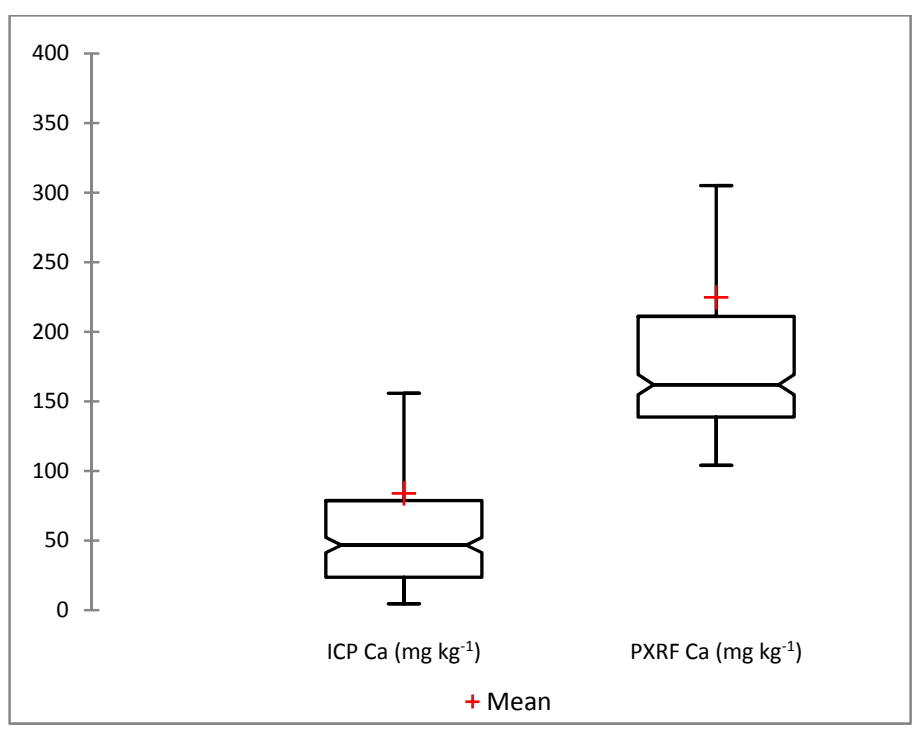



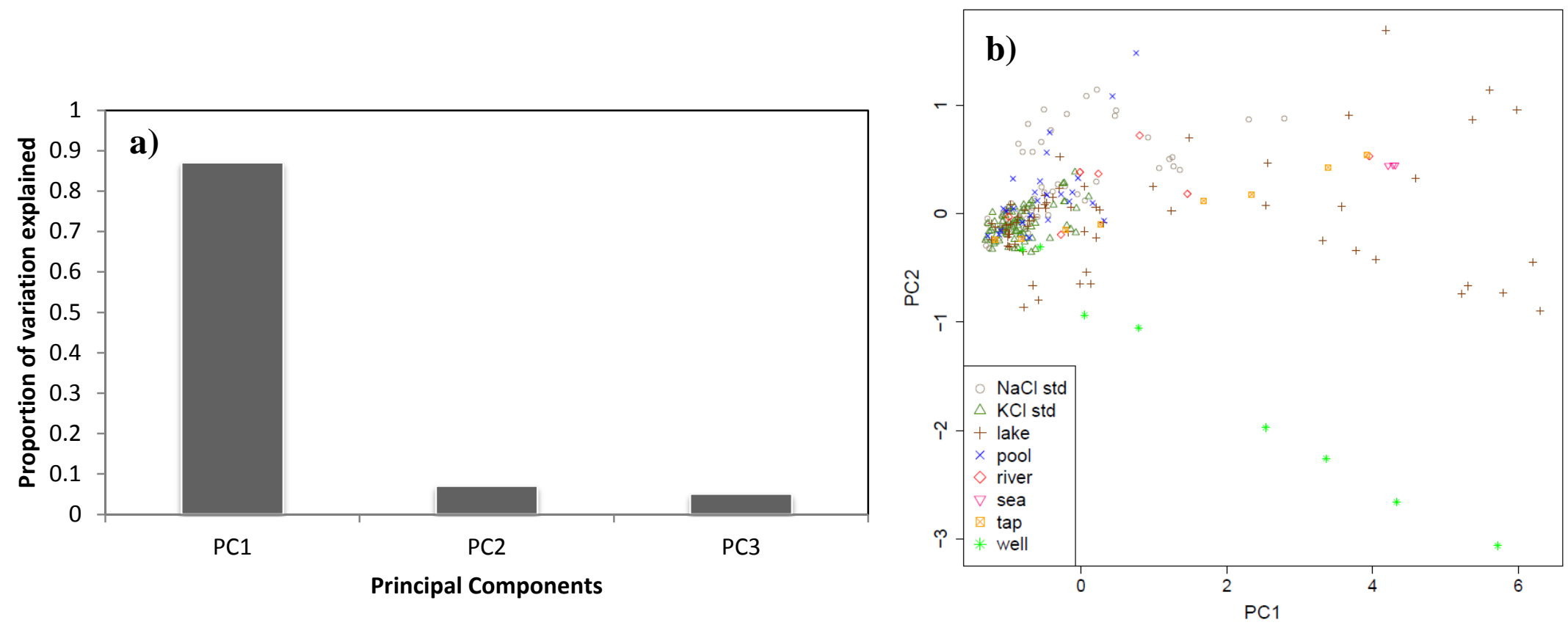

Fig. 3. 

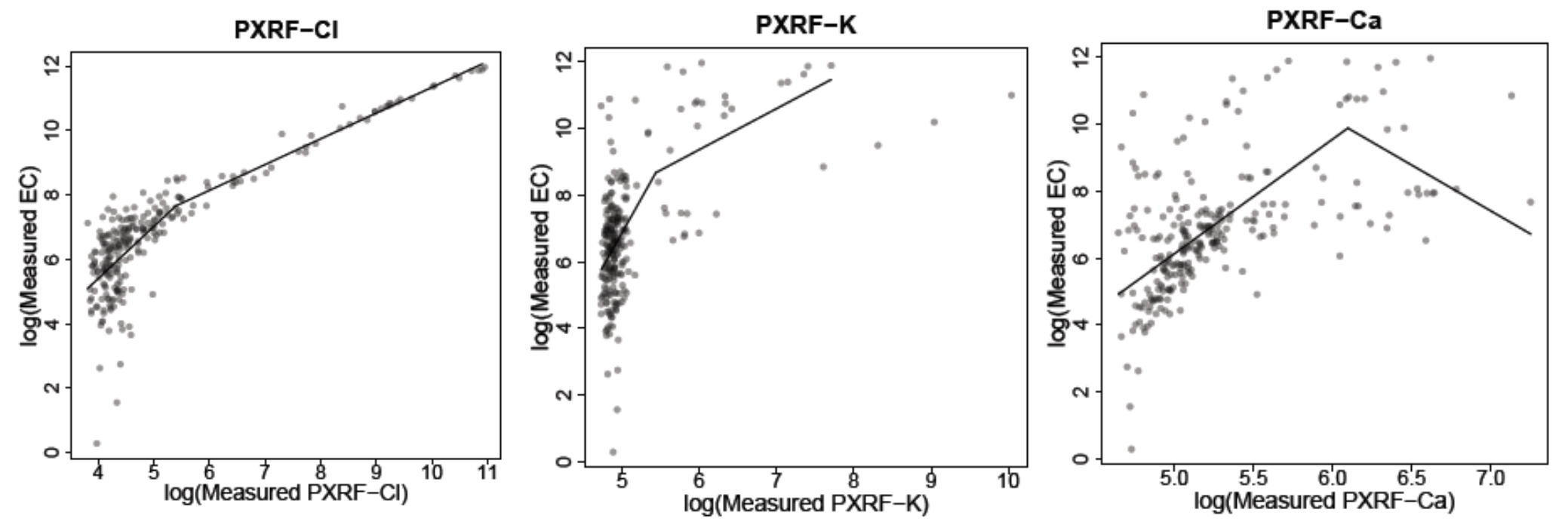

Fig. 4. 

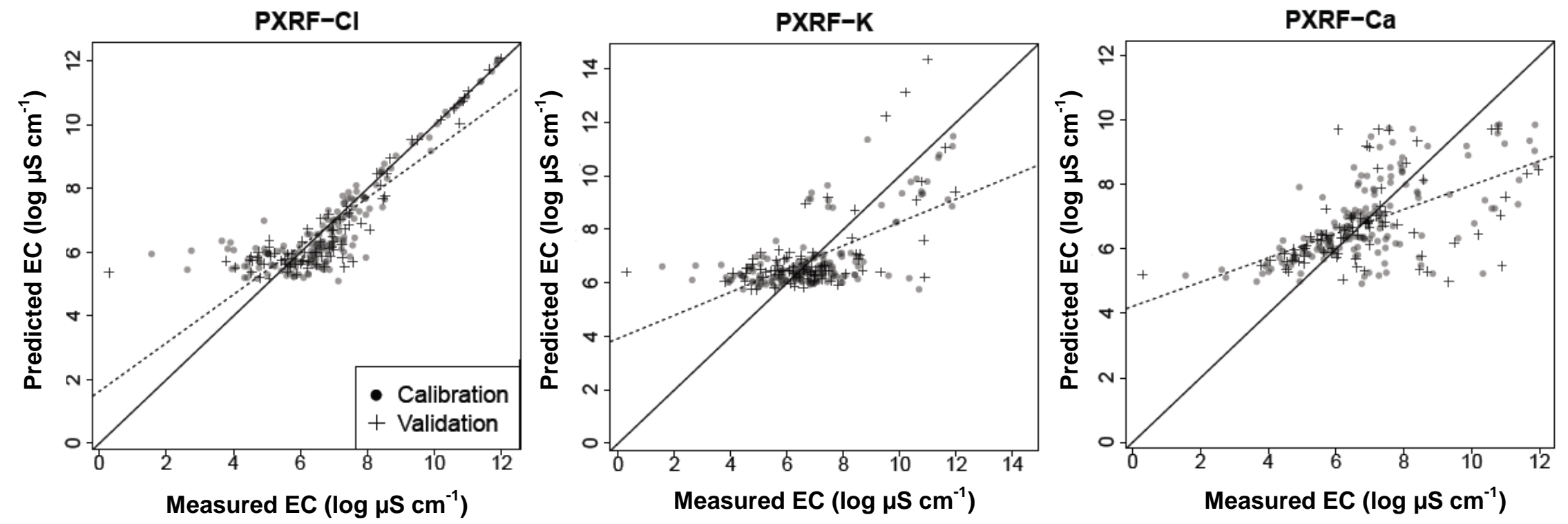

Fig. 5. 

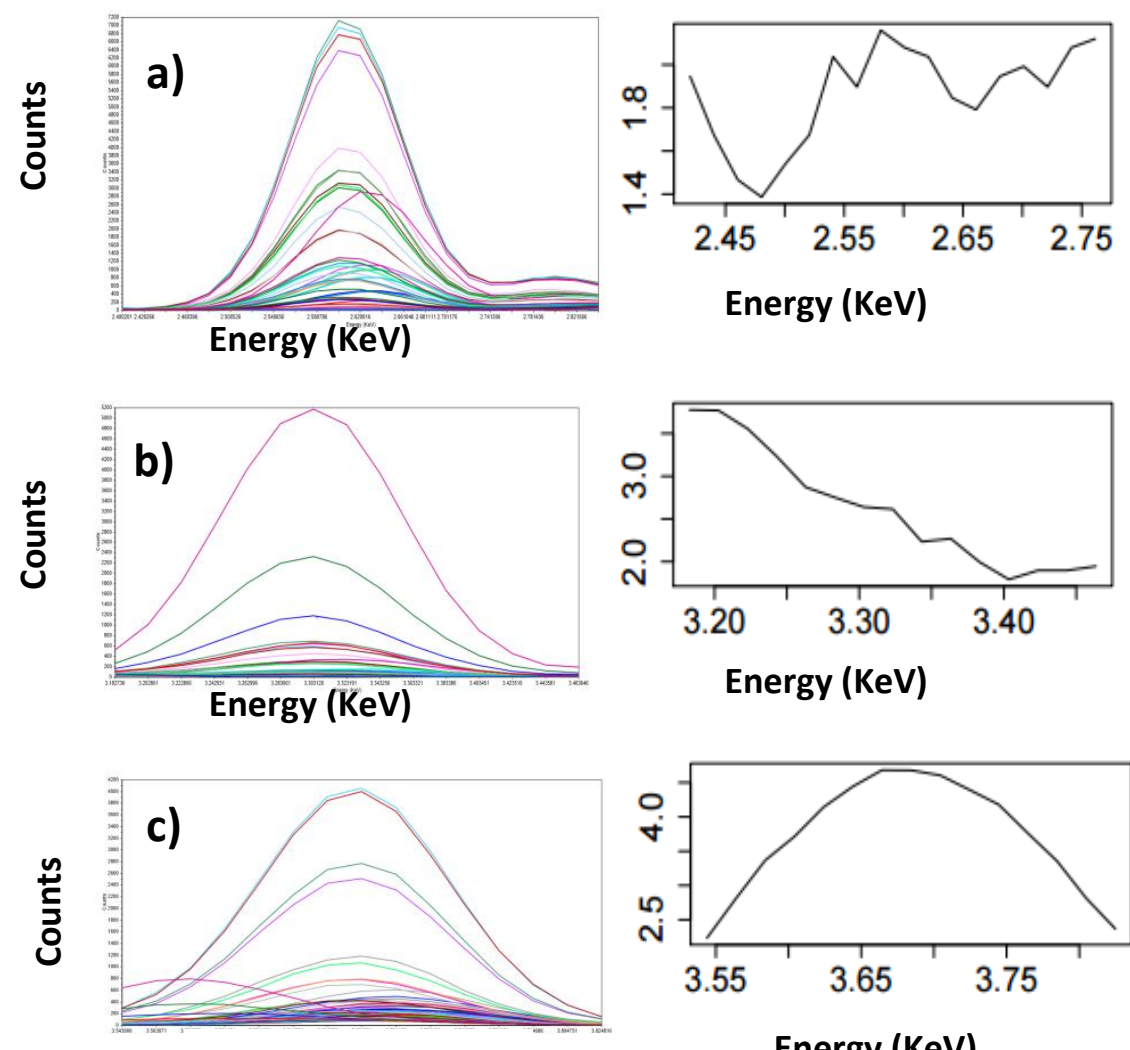

Energy (KeV)
Energy (KeV)
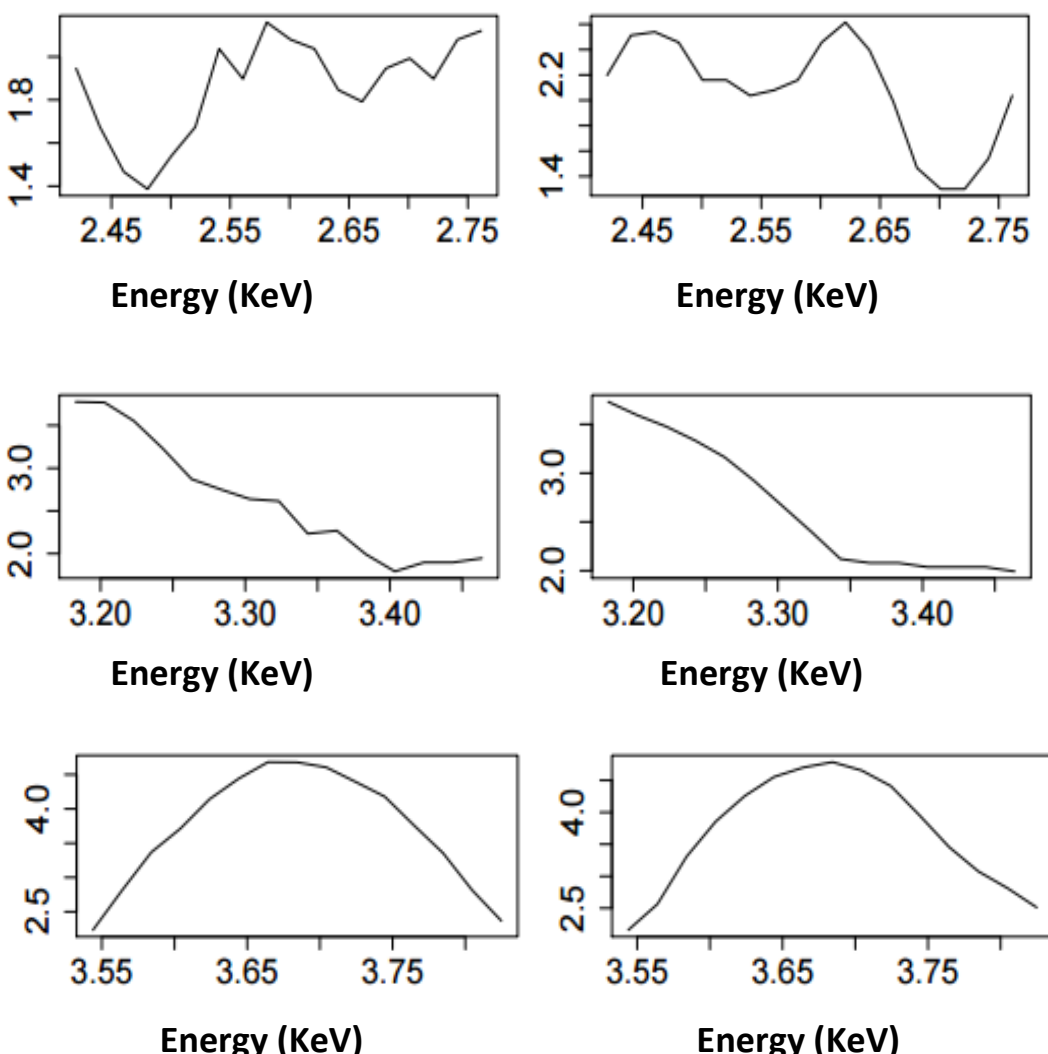

Energy (KeV)
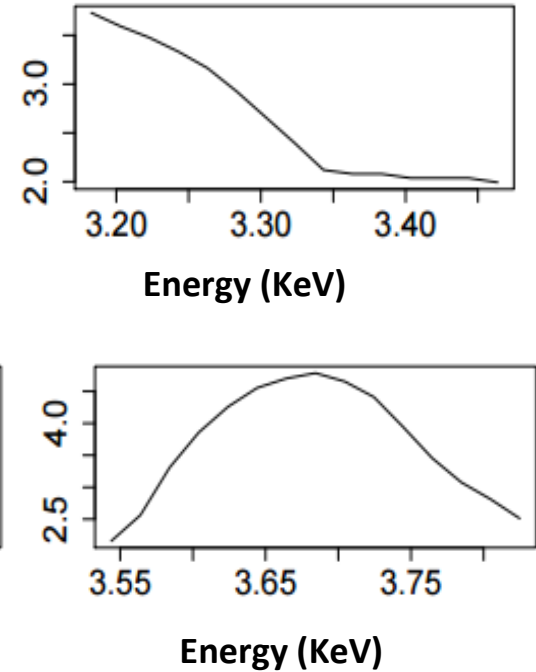
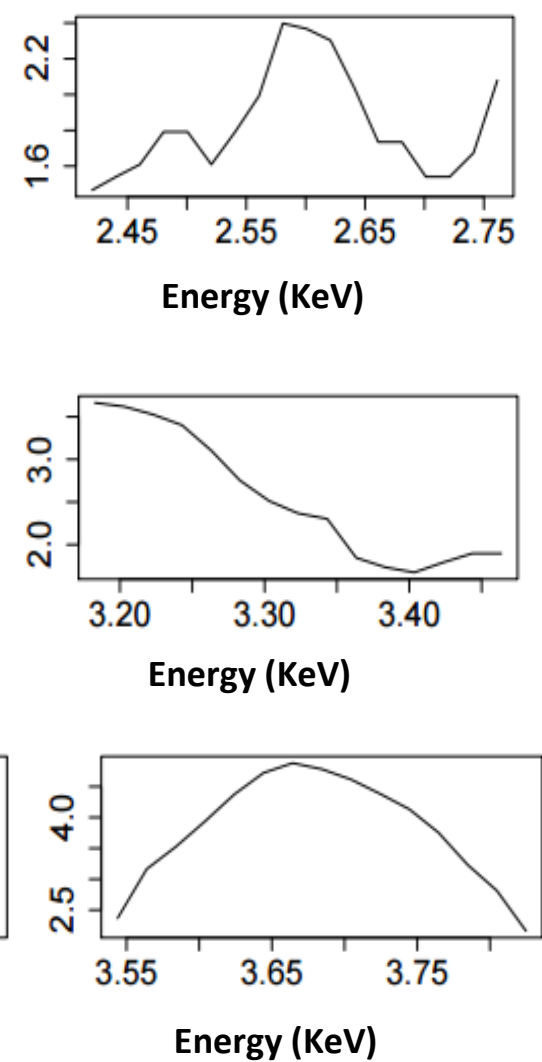

Fig. 6. 
Table 1. Locations where water samples were collected both within the United States and internationally.

\begin{tabular}{llll}
\hline Country & $\boldsymbol{n}$ & State & $\boldsymbol{n}$ \\
\hline Belgium & 1 & Alaska & 5 \\
Bolivia & 5 & Arkansas & 9 \\
Brazil & 10 & Arizona & 35 \\
Curacao & 3 & California & 1 \\
Honduras & 3 & Colorado & 17 \\
Italy & 10 & Florida & 6 \\
Mexico & 8 & Minnesota & 1 \\
Romania & 8 & Mississippi & 5 \\
Trinidad & 1 & New Mexico & 40 \\
United States & 207 & Nevada & 14 \\
Total: & $\mathbf{2 5 6}$ & Oklahoma & 8 \\
& & Tennessee & 1 \\
& & Texas & 30 \\
& & Utah & 28 \\
& & Wyoming & 7 \\
& & Total: & $\mathbf{2 0 7}$ \\
\hline
\end{tabular}


Table 2. Summary statistics of water EC, PXRF sensed elements and ICP measured elements.

\begin{tabular}{lccccc}
\hline \multicolumn{1}{c}{ Parameter } & $\boldsymbol{n}$ & Minimum & Maximum & Mean & Std. deviation \\
\hline $\left.\mathrm{EC}(\mu \mathrm{S} \mathrm{cm})^{-1}\right)$ & 252 & 1.33 & 157600.00 & 7837.55 & 24046.46 \\
$\mathrm{ICP} \mathrm{Cl}\left(\mathrm{mg} \mathrm{kg}^{-1}\right)$ & 252 & 0.10 & 3688.79 & 413.33 & 957.03 \\
PXRF Cl $\left(\mathrm{mg} \mathrm{kg}^{-1}\right)$ & 252 & 45.00 & 56739.00 & 1968.07 & 7625.02 \\
$\mathrm{ICP} \mathrm{K}\left(\mathrm{m} \mathrm{kg} \mathrm{k}^{-1}\right)$ & 252 & 0.31 & 846.45 & 69.90 & 179.09 \\
PXRF K $\left(\mathrm{mg} \mathrm{kg}^{-1}\right)$ & 252 & 113.00 & 22901.00 & 331.15 & 1557.70 \\
$\mathrm{ICP} \mathrm{Ca}\left(\mathrm{mg} \mathrm{kg}^{-1}\right)$ & 252 & 4.55 & 1105.17 & 84.03 & 131.45 \\
PXRF Ca $\left(\mathrm{mg} \mathrm{kg}^{-1}\right)$ & 252 & 104.00 & 1410.00 & 224.85 & 174.34 \\
\hline
\end{tabular}


Table 3. Pearson's correlation matrix of PXRF sensed elements and ICP measured elements.

\begin{tabular}{lrrrrrr}
\hline \multicolumn{1}{c}{ Variables } & $\begin{array}{c}\mathrm{ICP} \mathrm{Cl} \\
\left(\mathrm{mg} \mathrm{kg}^{-1}\right)\end{array}$ & $\begin{array}{c}\text { PXRF Cl } \\
\left(\mathrm{mg} \mathrm{kg}^{-1}\right)\end{array}$ & $\begin{array}{c}\text { ICP K } \\
\left(\mathrm{mg} \mathrm{kg}^{-1}\right)\end{array}$ & $\begin{array}{c}\text { PXRF K } \\
\left(\mathrm{mg} \mathrm{kg}^{-1}\right)\end{array}$ & $\begin{array}{c}\text { ICP Ca } \\
\left(\mathrm{mg} \mathrm{kg}^{-1}\right)\end{array}$ & $\begin{array}{c}\text { PXRF Ca } \\
\left(\mathrm{mg} \mathrm{kg}^{-1}\right)\end{array}$ \\
\hline ICP Cl $\left(\mathrm{mg} \mathrm{kg}^{-1}\right)$ & $\mathbf{1}^{\mathrm{a}}$ & & & & & \\
PXRF Cl $\left(\mathrm{mg} \mathrm{kg}^{-1}\right)$ & $\mathbf{0 . 6 9}$ & $\mathbf{1}$ & & & & \\
ICP K $\left(\mathrm{mg} \mathrm{kg}^{-1}\right)$ & $\mathbf{0 . 7 1}$ & $\mathbf{0 . 6 1}$ & $\mathbf{1}$ & & & \\
PXRF K $\left(\mathrm{mg} \mathrm{kg}^{-1}\right)$ & $\mathbf{0 . 3 4}$ & $\mathbf{0 . 2 2}$ & $\mathbf{0 . 2 0}$ & $\mathbf{1}$ & $\mathbf{1}$ & \\
ICP Ca $\left(\mathrm{mg} \mathrm{kg}^{-1}\right)$ & $\mathbf{0 . 3 2}$ & $\mathbf{0 . 2 4}$ & $\mathbf{0 . 3 2}$ & -0.031 & $\mathbf{0 . 6 0}$ & \\
PXRF Ca $\left(\mathrm{mg} \mathrm{kg}^{-1}\right)$ & $\mathbf{0 . 3 3}$ & $\mathbf{0 . 2 9}$ & $\mathbf{0 . 2 2}$ & 0.006 & $\mathbf{1}$ \\
\hline
\end{tabular}

${ }^{\mathrm{a}}$ Values in bold are different from 0 with a significance level alpha $=0.05$ 
Table 4. Water EC model statistics using PXRF measured elements as predictors.

\begin{tabular}{|c|c|c|c|c|c|c|c|}
\hline $\begin{array}{l}\text { Predictor } \\
\text { (log transformed) }\end{array}$ & Model $^{\mathrm{a}}$ & $\begin{array}{r}\text { Calibration } \\
\mathbf{R}^{2}\end{array}$ & $\begin{array}{r}\mathbf{R M S E}_{\text {cali }}^{\mathbf{b}} \\
\left(\log \mu \mathrm{Sm}^{-1}\right)\end{array}$ & $\begin{array}{r}\text { Validation } \\
\mathbf{R}^{2}\end{array}$ & $\begin{array}{r}\mathbf{R M S E}_{\mathrm{vali}^{\mathbf{c}}} \\
\left(\log \mu \mathrm{S} \mathrm{cm}^{-1}\right)\end{array}$ & $\mathrm{AIC}^{\mathrm{d}}$ & BIC $^{\mathrm{e}}$ \\
\hline PXRF Cl $\left(\mathrm{mg} \mathrm{kg}^{-1}\right)$ & $\overline{\text { PLR }}$ & 0.77 & 0.89 & 0.77 & 0.95 & 468.74 & 484.59 \\
\hline PXRF K (mg kg-1) & PLR & 0.41 & 1.41 & 0.31 & 1.66 & 630.65 & 646.50 \\
\hline $\operatorname{PXRF} \mathrm{Ca}\left(\mathrm{mg} \mathrm{kg}^{-1}\right)$ & PLR & 0.41 & 1.40 & 0.18 & 1.81 & 628.67 & 644.52 \\
\hline
\end{tabular}

${ }^{\mathrm{a}} \mathrm{PLR}$, piecewise linear regression.

${ }^{\mathrm{b}} \mathrm{RMSE}_{\text {cali }}$, root mean squared error of calibration.

${ }^{\mathrm{c}} \mathrm{RMSE} \mathrm{E}_{\mathrm{vali}}$, root mean squared error of validation.

${ }^{\mathrm{d}}$ AIC, Akaike information criterion.

${ }^{\mathrm{e}} \mathrm{BIC}$, Bayesian information criterion. 
Table 5. Water EC calibration model equations $(\mathrm{n}=176)$ using PXRF measured elements as predictors.

\begin{tabular}{|c|c|c|}
\hline $\begin{array}{l}\text { Predictor } \\
(\log \text { transformed })\end{array}$ & Model $^{\mathrm{a}}$ & Calibration model equation \\
\hline $\mathrm{PXRF} C l\left(\mathrm{mg} \mathrm{kg}^{-1}\right)$ & PLR & $\log (\mathrm{EC})=-1.070+1.620 * \log (\mathrm{PXRF}-\mathrm{Cl})-0.820 * \log (\mathrm{PXRF}-\mathrm{Cl}) * 1[\log (\mathrm{PXRF}-\mathrm{Cl})>5.379]^{\mathrm{b}}$ \\
\hline PXRF K (mg kg $\left.{ }^{-1}\right)$ & PLR & $\log (\mathrm{EC})=-13.780+4.132 * \log (\mathrm{PXRF}-\mathrm{K})-2.899 * \log (\mathrm{PXRF}-\mathrm{K}) * 1[\log (\mathrm{PXRF}-\mathrm{K})>5.434]$ \\
\hline PXRF Ca $\left(\mathrm{mg} \mathrm{kg}^{-1}\right)$ & PLR & $\log (\mathrm{EC})=-11.078+3.442 * \log (\mathrm{PXRF}-\mathrm{Ca})-6.104 * \log (\mathrm{PXRF}-\mathrm{Ca}) * 1[\log (\mathrm{PXRF}-\mathrm{Ca})>6.084]$ \\
\hline
\end{tabular}



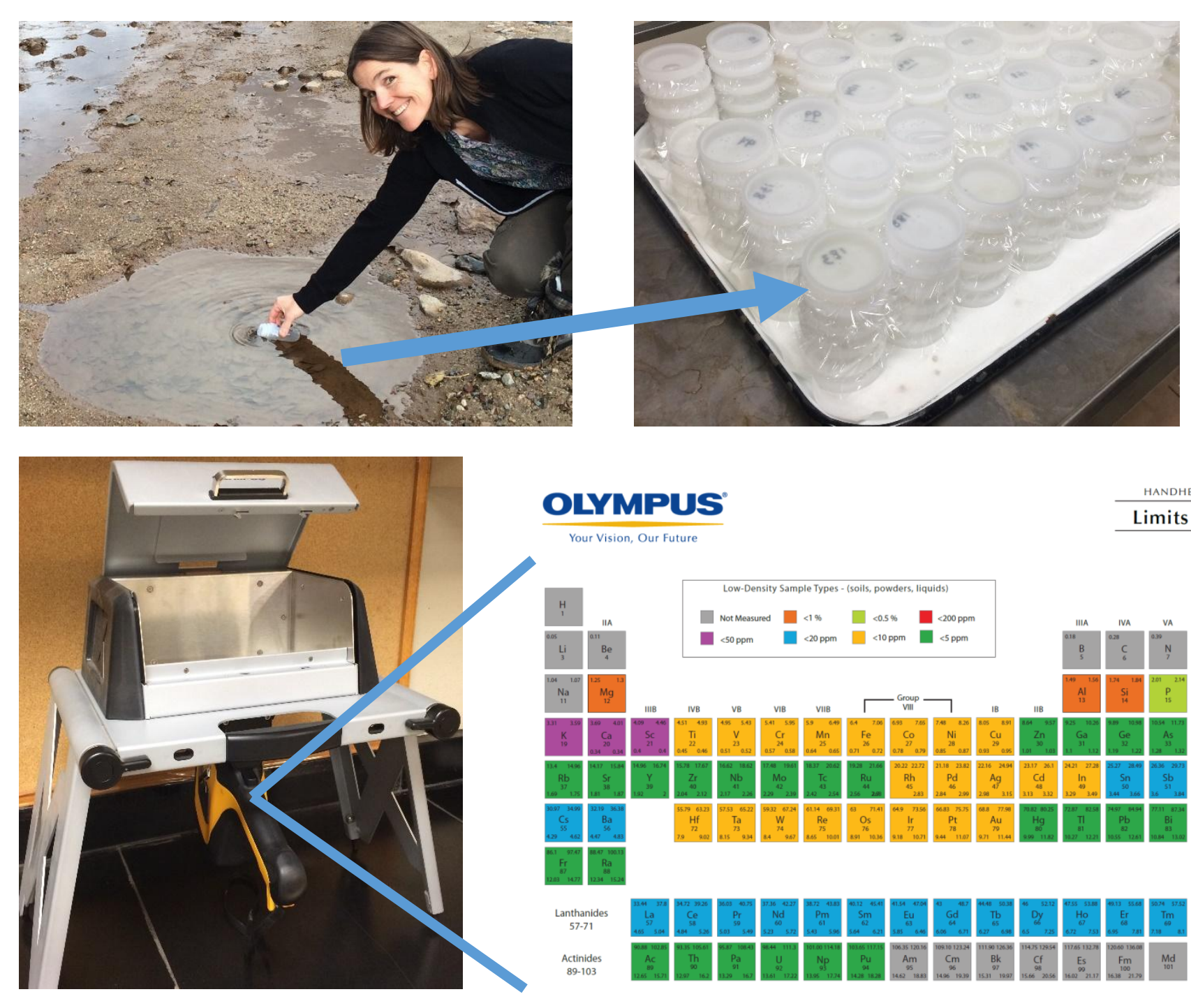

OLYMPUS

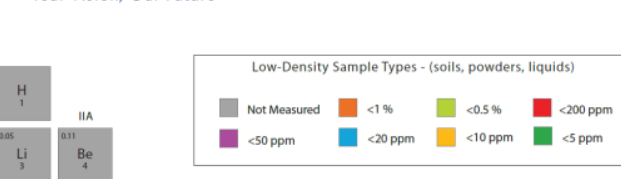

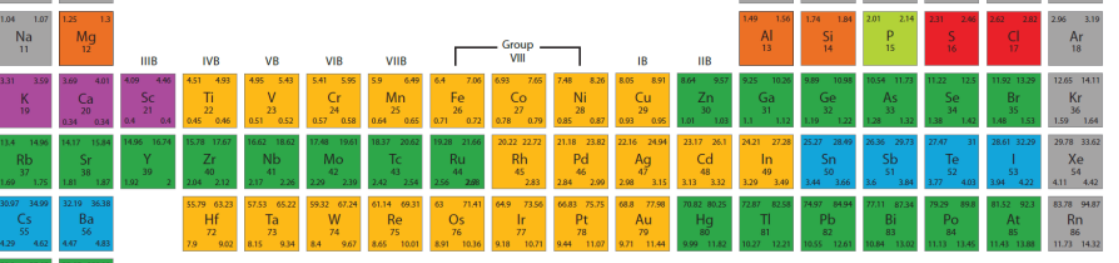

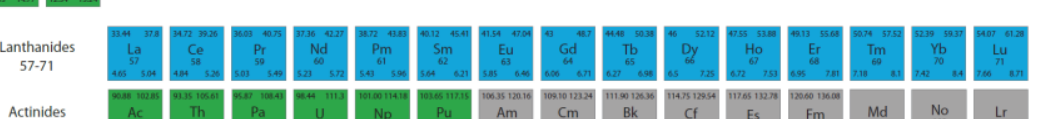

Limits of Detection
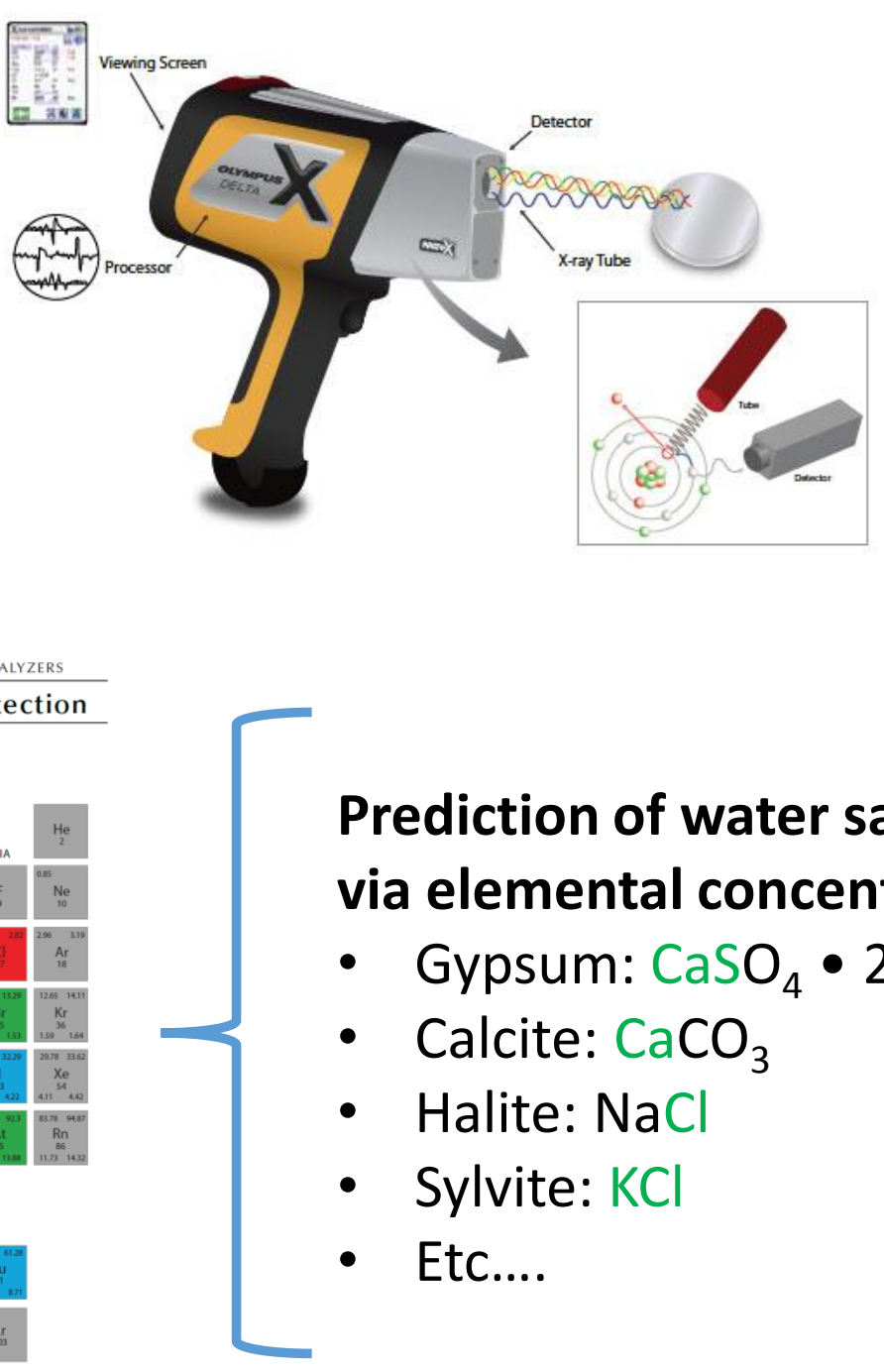

Prediction of water salinity
via elemental concentration:
- Gypsum: $\mathrm{CaSO}_{4} \cdot 2 \mathrm{H}_{2} \mathrm{O}$
- Calcite: $\mathrm{CaCO}_{3}$

Prediction of water salinity
via elemental concentration:
- Gypsum: $\mathrm{CaSO}_{4} \cdot 2 \mathrm{H}_{2} \mathrm{O}$
- Calcite: $\mathrm{CaCO}_{3}$

- Halite: $\mathrm{NaCl}$

- Sylvite: $\mathrm{KCl}$

- Etc....
Prediction of water salinity
via elemental concentration:
- Gypsum: $\mathrm{CaSO}_{4} \cdot 2 \mathrm{H}_{2} \mathrm{O}$
- Calcite: $\mathrm{CaCO}_{3}$

Prediction of water salinity
via elemental concentration:
- Gypsum: $\mathrm{CaSO}_{4} \cdot 2 \mathrm{H}_{2} \mathrm{O}$
- Calcite: $\mathrm{CaCO}_{3}$

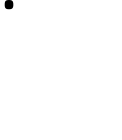

Etc... 